\title{
Creating a Pharmacy Internship: A Toolbox for Success
}

Sarah A. Nisly, PharmD, BCPS, FCCP 1,2; Lisa F. Brennan, PharmD, BCPS, BCGP ${ }^{1,2}$; Lauren Verbosky, PharmD, $M S^{3}$; Alexandre Raymond, PharmD, $M S^{4}$; Jennifer Tryon, PharmD, MS, FASHP2

${ }^{1}$ Wingate University, Wingate, North Carolina; ${ }^{2}$ Wake Forest Baptist Medical Center, Winston-Salem, North Carolina

${ }^{3}$ BayCare Health System, Clearwater, Florida; ${ }^{4}$ Ochsner Medical Center, Jefferson, Louisiana

\begin{abstract}
Objective: To describe available compensated student internships and provide guidance for new program development. Methods: A search was conducted using PubMed, MEDLINE, and Google with the following search terms: pharmacy, intern, internship, and student. All English language publications were considered for inclusion. Articles describing IPPE or APPE student utilization were excluded.

Key findings: Pharmacy student internship programs are common in practice, though there are few with published outcome data. Most often, interns serve as pharmacist extenders and participate in activities that center around extension of pharmacy services within the institution. Development of new programs should include partnering with nearby pharmacy programs and state boards of pharmacy to develop a well matched curriculum and allow for interns to practice at the top of their license. Lastly, outcomes should be measured and disseminated for the benefit of the academy. Additional considerations for developing a student internship program and guidance are provided.

Conclusions: Although in existence for decades, minimal published reports showcase institutional outcomes associated with student internships. No data is available to show the downstream effect an internship can have on direct patient care activities.
\end{abstract}

Keywords: pharmacy internship, community, health-system, student, development

\section{INTRODUCTION}

Internship programs complement pharmacy graduate education through direct application of curricular coursework and fostering of personal and professional skills. ${ }^{1-10}$ The American Society of Health-System Pharmacists (ASHP) defines an internship as an on-the-job training program that provides for the development of a student into a competent practitioner through basic practice experiences. ${ }^{11}$ Student interns can have a wide variety of responsibilities, including expansion of clinical services, medication distribution, and quality improvement or research project completion. Intern training may also serve as a recruitment and training venue to fill available full-time equivalents and provide on-the-job training. There is a void of literature describing the curriculum of existing internship programs. Likewise, the wide variety of program types, intern activities, and outcomes assessed leave little structured guidance for creative development of an internship program. This article aims to: 1 ) describe the structure, activities, and outcomes of compensated student internship programs and 2) provide guidance for development and execution of a professional student internship program.

Corresponding author: Sarah A. Nisly, PharmD, BCPS, FCCP Associate Professor of Pharmacy, Wingate University Clinical Specialist, General Medicine Wake Forest Baptist Medical Center 515 N. Main Street, Wingate, NC 28174 Phone: (336)713-1938; Email: s.nisly@wingate.edu

\section{METHODS}

A search was conducted using PubMed, MEDLINE, and Google with the following search terms: pharmacy, intern, internship, and student. All English language publications were considered for inclusion. Articles describing IPPE or APPE student utilization were excluded.

\section{KEY FINDINGS}

The role of pharmacy student internships focuses on three overarching principles: to build upon students' knowledge of clinical and operational pharmacy practice, to develop competent pharmacists upon graduation with the possibility for retention, and to build mentor-mentee relationships for further career advancement. As such, student interns often serve as pharmacist extenders in the delivery of pharmaceutical care within their respective internship program. Each internship program is varied by institutional needs, and institutional benefits to an internship program have been published. ${ }^{1-10}$ Programs with published quantifiable outcomes are highlighted in Supplemental File 1 while those with descriptive outcomes are presented in Supplemental File 2.

A variety of pharmacy practice internships in diverse fields exists, including clinical services, ${ }^{1,3-4,6-9}$ community pharmacy, ${ }^{2}$ drug distribution, ${ }^{5-6,9,10}$ healthcare within the federal government, ${ }^{12}$ industry, ${ }^{13}$ and organizational management. ${ }^{14}$ Each presents a unique opportunity for student development despite similarities in capacity for skill set refinement. Currently, no single location exists for all student internship descriptions and applications. Most programs have a website 
available for information, easily accessible through an online search engine. Additionally, many national organizations serve as a platform to direct students to different programs. ${ }^{15-17}$

\section{Health-System or Hospital Pharmacy Internships}

Health-system pharmacy internships are the most commonly reported program type and provide students exposure to operational and clinical areas of pharmacy practice within a hospital or healthcare system. Often interns participate in delivery of care through operational activities such as dispensing, packaging, and stocking areas within the healthsystem. ${ }^{1,3-10}$ Additionally, interns may participate in direct patient care through medication reconciliation and education, among other activities (Appendices 1 and 2). Health-system pharmacy internships vary in duration, with two dominant formats: an extensive, all-inclusive summer experience or a longitudinal experience encompassing the summer and academic semesters. Longitudinal internship programs offer an opportunity to increase clinical and operational responsibilities as students progress through their pharmacy education. For instance, first-year interns may start in a primarily operational role with responsibilities including dispensing medications, nonsterile compounding, stocking, and answering incoming calls to assist the medication use process. ${ }^{1,10,18}$ More advanced intern roles can include, but are not limited to, sterile compounding, identifying and recommending intravenous to by mouth interchanges, clinical dose adjustment recommendations, and assisting in transitions of care. ${ }^{1,6,10,18}$ Lastly, internships may be able to incorporate interns in advanced pharmacist extender roles under the discretion of institution and state regulations. ${ }^{1,5,19}$

In addition to clinical and operational responsibilities, internships provide a rich learning environment for research, enhancement of verbal and written communication skills, and a focus on the importance of mentorship and practice leadership. ${ }^{1,6-7} \quad$ Some programs report benefits from administrative contributions of student interns, such as management of delivery technicians while serving as distribution coordinator, completion of process improvement projects, development of policies, procedures, and training activities and their assessment. ${ }^{1,4-6,8}$ Institutional research benefits reported include drug utilization reviews, drug information services, and data collection and analysis for various department initiatives. ${ }^{1,4,6,8}$

\section{Non Health-System Pharmacy Internships}

While the majority of published data exists for health-system pharmacy internships, there is some literature describing community pharmacy internship. . $^{215,20}$ Similar to health-system pharmacy internships, community pharmacy internships can be for the summer only or extend longitudinally throughout the academic year. First-year intern responsibilities may include preparation of medications, pharmacy management responsibilities regarding laws and ethics, or team building activities. Progression to prescription counseling, participation in pharmacy audits, and record keeping may occur over time. ${ }^{2}$ Published data for community interns focus on clinical interventions, description of practice management exposure for the intern, and retention. ${ }^{2}$ A unique aspect to community pharmacy internships is the opportunity for a corporate internship. Corporate interns spend the summer months at the corporation's regional or executive offices experiencing the leadership and administrative side of pharmacy. ${ }^{20}$

Pharmacy internships are not exclusively for students interested in health-system or community practice. The federal government, managed care institutions, pharmaceutical and biotech industries, and professional organizations all offer pharmacy internship opportunities. ${ }^{12-14}$ However, published research regarding intern experiences outside of community or health-system based practice is unavailable to date.

Regardless of the internship, personnel benefits have been documented in the literature, focusing primarily on time and cost savings in shifting tasks from pharmacists and technicians to student interns but also including reporting of task volume performed by interns (Supplemental File 1) ${ }^{1-4}$ One longitudinal program reported their intern program led to a cost savings of $\$ 7236$ in reduced overtime pay, in addition to helping meet patient counseling goals. ${ }^{1}$ Personnel benefit can also derive from retaining well-trained students after graduation, reducing recruitment costs and initial training time as well as vacancy rate, and increasing staff satisfaction. ${ }^{6,8}$

\section{Considerations for Implementing a Student Internship}

A carefully planned pharmacy internship can provide a powerful experience for student learners and allow pharmacy service expansion within a practice environment. Table 1 was created based on the aforementioned literature, personal experience, and through discussions with other internship programs. It is designed to serve as a start-up checklist for programs interested in developing a student internship.

Several considerations merit discussion prior to implementing an internship, including scope of practice and licensing variations by state or country, budget justification, and academic partnerships with colleges and schools of pharmacy. Internship directors should collaborate with regulatory bodies to ensure that student activities and oversight allow for interns to practice at the top of their licenses., ${ }^{5,19}$ Similar to a residency advisory committee, a group of mentors and preceptors can be used to develop outcomes for the program, create a reporting structure, and develop evaluation forms for performance. This team can also be responsible for collecting and analyzing program metrics.

Documentation of activities can help cost justify services provided and showcase intern accomplishments. If one of the commercially available programs for assignment of monetary value to each activity is not readily available, comparative 
literature and institution specific financial data can be used to create a unique cost analysis. ${ }^{3,21-22}$ Finally, partnership with area colleges or schools of pharmacy allows for alignment of intern activities, curricular coursework, and a consistent stream of intern applicants.

While student interns can be utilized to accomplish a variety of patient care and non-patient care activities, the educational focus must be preserved. A routine mechanism for measuring growth, providing feedback, and aligning activities with the goals of the learner are key components to a successful program. When skill proficiency is achieved, additional challenges or expectations should be incorporated to provide ongoing learning opportunities. This could be done in a format similar to the ASHP PGY1 standards for residency training. ${ }^{23-24}$

Beyond traditional metrics highlighted in Appendices 1 and 2, the commentary published in this issue suggests additional developmental metrics. This can include changes in mindset or resilience and development of leadership using validated tools. Regardless of what outcomes are measured, disseminating program structure, intern performance, and lessons learned would benefit the profession.

Table 1. Student Internship Checklist

\begin{tabular}{|c|c|}
\hline $\begin{array}{c}\text { Phase of Program } \\
\text { Development }\end{array}$ & Recommendations \\
\hline Initial Considerations & $\begin{array}{l}\text { - } \text { Review state licensure requirements and scope of practice } \\
\text { - Understand the partnerships between the organization and the pharmacy } \\
\text { - } \text { Obllege or school } \\
\text { - } \quad \text { Review the number of IPPE hours required for each school } \\
\text { - } \quad \text { Determine number of interns and respective salaries } \\
\text { - } \quad \text { Identify the internship director and preceptors } \\
\text { - } \quad \text { Create the reporting structure } \\
\text { - } \quad \text { Identify mentors, consider seasoned interns as options } \\
\text { - } \quad \text { Develop objectives, goals, and outcomes for the program } \\
\text { - } \quad \text { Develop learning objectives and expectations for each intern } \\
\text { - } \quad \text { Identify evaluation forms and feedback mechanisms and frequency } \\
\text { - } \quad \text { Identify an individual who is responsible for collecting and analyzing the } \\
\text { documentation } \\
\text { Determine the list of activities (patient care and non-patient care) and } \\
\text { appropriate ways for documentation }\end{array}$ \\
\hline $\begin{array}{l}\text { Evaluation and Reporting } \\
\text { Considerations }\end{array}$ & $\begin{array}{l}\text { - Develop metrics and targets for each activity } \\
\circ \text { Explore options within electronic medical record and computer } \\
\text { programs } \\
\circ \quad \text { Ensure activities align with pharmacy college or school curriculum } \\
\text { - Collect evaluation forms and synthesize feedback } \\
\text { - } \quad \text { Report information and results to relevant parties } \\
\text { - Disseminate findings through presentations and scholarship }\end{array}$ \\
\hline
\end{tabular}

\section{DISCUSSION}

As pressure to provide value (defined as high quality at a lower cost) in healthcare increases, utilization of student resources is a natural path to extend pharmacy services and demonstrate medication management outcomes. Recent reports have focused on incorporation of IPPE and APPE students to lengthen the reach of the pharmacy department. ${ }^{25-28}$ While this is proving to add value to institutions precepting student experiences, internships differ by providing a consistent trained employee to provide sustainable services over time. ${ }^{29}$
Student interns offer a unique advantage to institutions by decreasing on-boarding, increasing responsibilities over a longer time period, and increasing institution retention, as well as commitment to the institution as an employee. A paid internship also gives financially dependent students an option in seeking pharmacy experience while completing curricular coursework. Defining institutional needs while revisiting intern responsibilities can increase value to your department, institution, and patients. Programmatic outcomes and progress measurement within the internship program can 
serve as quality improvement metrics for the program over time. A structured implementation plan, routine metric collection, and quality assurance process will help any institution be successful in establishing or growing a student internship program.

In addition to monetary compensation, a well-structured internship program provides students exposure to all aspects of pharmacy practice. A majority of programs rotate students through multiple areas of the pharmacy and gradually increase complexity of tasks and responsibility. Direct patient and healthcare provider interaction further strengthen communication and listening skills. Internship students often gain exposure outside the institution as well, with many programs reporting student participation in regional or national professional meetings through attendance and poster presentations. $^{1,4}$

The benefit of experience gained by these students is difficult to quantify, with available published reports inferring a benefit from this experience by reporting the placement of students after completion of internships. Most students completing an internship go on to advanced practice sites such as postgraduate training or specialty practice. ${ }^{1,4-8}$ As previously stated, many students remain at the institution where they completed their internship. The UPMC health-system reported salary incentives to entice the interns to remain in the health-system, both in increased salary based on the number of years of internship as well as a lump sum bonus for early commitment. ${ }^{6}$ While this practice may not be feasible for all institutions, it does reflect the value institutions place on internship training.

\section{CONCLUSION}

Interns can provide value to an institution through completion of operational, clinical, and research tasks, acting as pharmacist extenders while gaining useful experience that can lead to advantageous employment opportunities. Limited data has been published showcasing the use of pharmacy student interns to complement activities traditionally done by pharmacists. As the pharmacy profession aims to achieve the Practice Advancement Initiative set forth by ASHP, it is necessary to create innovative solutions and share collaborative experiences. Student internship programs can bridge the gap between curricular course work and application to direct patient care activities. The steps provided in this article can serve as guidance to institutions to develop internships beneficial to both the student and the employer. These institutions can then contribute to the body of literature on their internship experiences, in order to continue to improve/develop pharmacy education and practice.

Acknowledgements: None

Funding/Support: None

Other Disclosures: None

\section{REFERENCES}

1. Amerine LB, Valgus JM, Moore JD, Arnall JR, Savage SW. Implementation of a longitudinal early immersion student pharmacist health system internship program. Curr Pharm Teach Learn. 2017; 9(3):421-6. doi: 10.1016/j.cptl.2017.01.011.

2. Pattin AJ, Kelling SE, Szyskowski J, Izor ML, Findley S. The redesign of a community pharmacy internship program. J Pharm Pract. 2016; 29(3):224-7. doi: $10.1177 / 0897190014566305$.

3. Kanz, B. Cost analysis of a pharmacy intern program at a tertiary academic medical center. (2014). MPA/MPP Capstone Projects. 10. https://uknowledge.uky.edu/mpampp_etds/10. Accessed December 7, 2018.

4. Skledar SJ, McKaveney TP, Ward CO, Culley CM, Ervin KC, Weber RJ. Advanced practice internship: experiential learning in a drug use and disease state management program. Am J Pharm Educ. 2006; 70(3): Article 68.

5. Gillis CM, Anger KE, Cotugno MC. Enhanced responsibilities for pharmacy interns at a teaching hospital. J Am Pharm Assoc. 2015; 55(2):198-202. doi: 10.1331/JAPhA.2015.14022.

6. Skledar SJ, Martinelli B, Wasicek K, Mark S, Weber RJ. Training and recruiting future pharmacists through a hospital-based student internship program. Am J Health-Syst Pharm. 2009; 66(17):1560-4. doi: 10.2146/ajhp080474.

7. Clark JS. Developing the future of pharmacy through health-system pharmacy internship programs. Am J Health Syst Pharm. 2007; 64(9):952-4. doi: 10.2146/ajhp060276

8. Payne GR, Tonnies F, Page T, Lee S, Stowers R, Geyer E, Estes DA. Regional cooperative summer internship program for pharmacy students. Am J Hosp Pharm. 1990; 47(8):1791-3.

9. Bair JN, Powell PJ. Structured competency-based hospital pharmacy internship program. Am J Hosp Pharm. 1981; 38(11):1705-8.

10. Karpinski T. Pharmacy Practice Model Initiative. Case Study: Expansion and restructuring of hospital pharmacy internship program. 2013. http://www.ashpmedia.org/pai/docs/casestudy_kar pinski_2.pdf. Accessed December 7, 2018.

11. American Society of Health-System Pharmacists Policy Positions 2009-2017. https://www.ashp.org//media/assets/policy-guidelines/docs/policypositions/policy-positions-education-training.ashx. Accessed December 7, 2018.

12. U.S. Food and Drug Administration. FDA Pharmacy Student Experiential Program. https://www.fda.gov/AboutFDA/WorkingatFDA/Fell owshipInternshipGraduateFacultyPrograms/Pharma cyStudentExperientialProgramCDER/default.htm.

Accessed December 7, 2018. 
13. International Society for Pharmaceutical Engineering. Companies with Internship Programs. https://ispe.org/membership/students/internshipprogram. Accessed December 7, 2018.

14. American Society of Health-System Pharmacists. ASHP Summer Internship. https://www.ashp.org/Pharmacy-Student/Programsand-Awards/ASHP-Summer-Internship. Accessed December 7, 2018.

15. National Community Pharmacists Association. http://www.ncpanet.org/. Accessed December 7, 2018.

16. Academy Managed Care Pharmacy. http://www.amcp.org/. Accessed December 7, 2018.

17. American Association of Colleges of Pharmacy. http://www.aacp.org/Pages/Default.aspx. Accessed December 7, 2018.

18. Nathan JP, Schilit S, Zerilli T, Shah B, Plotkin P, Tykhonova I. Functions performed by paid pharmacy interns in hospitals in New York. Am J Health-Syst Pharm. 2011; 68(2):165-8. doi: 10.2146/ajhp090674.

19. Vincent WR, Steink DT, Fink JL. State boards of pharmacy regulation of the supervision of pharmacist interns. Am J Pharm Educ. 2010; 74(1): Article 3.

20. Walgreens. Pharmacy Corporate Internship Program. https://jobs.walgreens.com/internships. Accessed December 7, 2018.

21. Senst BL, Achusim LE, Genest RP, Cosentino LA, Ford CC, Little JA, Raybon SJ, Bates DW. Practical approach to determining costs and frequency of adverse drug events in a health care network. Am J Health Syst Pharm. 2001; 58(12):1126-32.

22. Andrus MR, Stevenson TL, Eiland LS. Documentation of clinical interventions by pharmacy students and recent pharmacy graduates. Am J Health Syst Pharm. 2016; 73(23):1916-8. doi: 10.2146/ajhp160281.

23. American Society of Health-System Pharmacists. ASHP accreditation standard for postgraduate year one (PGY1) pharmacy residency programs. https://www.ashp.org/-/media/assets/professionaldevelopment/residencies/docs/pgy1-residencyaccreditation-standard-2016.ashx. Accessed December 7, 2018.

24. Starosta K, Davis SL, Kenney RM, Peters M, To L, Kalus JS. Creating objectives and measurable postgraduate year 1 residency graduation requirements. Am J Health Syst Pharm. 2017; 74(6):389-96. doi: 10.2146/ajhp160138.

25. Goodbar NH, Swarthout MD, Fraley MD, Stewart CL. Providing students with educational practice experiences that simulate practical work expectations. Am J Health Syst Pharm. 2016; 73(15):1124-5. doi: 10.2146/ajhp150502.

26. American College of Clinical Pharmacy, Rathbun RC, Hester EK, Arnold LM, Chung AM, Dunn SP, Harinstein LM, Leber M, Murphy JA, Schonder KS, Wilhelm SM, Smilie KB. Importance of direct patient care in advanced pharmacy practice experiences. Pharmacotherapy. 2012; 32(4):e88-97. doi: 10.1002/j.1875-9114.2012.01110.x.

27. Hardin HC, Hall AM, Roane TE, Mistry R. An advanced pharmacy practice experience in a student-staffed medication therapy management call center. Am J Pharm Educ. 2012; 76(6): Article 110. doi: 10.5688/ajpe766110.

28. Delgado O, Kernan WP, Knoer SJ. Advancing the pharmacy practice model in a community teaching hospital by expanding student rotations. Am J Health Syst Pharm. 2014; 71(21):1871-6. doi: 10.2146/ajhp130624.

29. Mersfelder TL, Bouthillier MJ. Value of the student pharmacist to experiential practice sites: A review of the literature. Ann Pharmacother. 2012; 46(4):541-8. doi: 10.1345/aph.1Q54. 